\title{
The perception of subjective contours and neon color spreading figures in young infants
}

\author{
Michael KaVŠEK \\ University of Bonn, Bonn, Germany
}

\begin{abstract}
The goal of the present habituation-dishabituation study was to explore sensitivity to subjective contours and neon color spreading patterns in infants. The first experiment was a replication of earlier investigations that showed evidence that even young infants are capable of perceiving subjective contours. Participants 4 months of age were habituated to a subjective Kanizsa square and were tested afterward for their ability to differentiate between the subjective square and a nonsubjective pattern that was constructed by rotating some of the inducing elements. Data analysis indicated a significant preference for the nonsubjective pattern. A control condition ensured that this result was not generated by the difference in figural symmetry or by the local differences between the test displays. In the second experiment, infant perception of a neon color spreading display was analyzed. Again, 4-month-old infants could discriminate between the illusory figure and a nonillusory pattern. Furthermore, infants in a control group did not respond to the difference in symmetry and the local differences between two nonillusory targets. Overall, the results show that young infants respond to illusory figures that are generated by either implicit T-junctions (Experiment 1) or implicit X-junctions (Experiment 2). The findings are interpreted against the background of the neurophysiological model proposed by Grossberg and Mingolla (1985).
\end{abstract}

The aim of the study was twofold. The first aim was to examine whether the findings of earlier studies, according to which young infants are able to discern subjective contours, could be replicated. More specifically, it was investigated whether infants 4 months of age are capable of detecting a subjective Kanizsa square (Figure 3A). Second, infants' responsiveness to a chromatic subjective contour - that is, to a neon color spreading figure - was tested (Figure 4A).

In the Kanizsa pattern depicted in Figures 1B/3A (Kanizsa, 1976), a subjective square is generated by four dark disks with cutouts (Pacman elements). More specifically, an illusory sharp-square border (illusory contour) is perceived surrounding an area of bright intensification (illusory brightness). In the case of a real square, the corners of which partly overlap each of the four disks, the points of contact between the square and the disks are characterized by T-junctions (see Figure 1A; see, e.g., Albert, 1999; Cavanagh, 1987). The top of the $\mathrm{T}$ is assumed to belong to the occluding square, whereas the stem of the $T$ is ascribed to the partially occluded disk. In the Kanizsa figure, however, the T-junctions are replaced by L-junctions (see Figure 1B). Nevertheless, since a (subjective) square lying in front of four circles is perceived, the L-junctions function as implicit T-junctions.

The classical descriptions of neon color spreading figures have been published by Varin (1971) and by van Tuijl (1975). Neon color spreading can be generated by continuing the inducing elements of a subjective figure inside the illusory surface and by allocating these segments a luminance different from that of the luminance of both the background and the inducing elements. The neon color spreading pattern in Figures 2B/4A is derived from the Kanizsa pattern shown in Figures 1B/3A. In Figure 2B, the luminance of the cutouts/segments does not equal the luminance of either the background or the inducing elements. In the display, a dark (subjective) semitransparent filter is seen that covers both the dark background and a part of each of the distinct circles. Figure $2 \mathrm{~B}$ is an achromatic version of neon color spreading. If the segments are colored, this color leaves the segments and fills the illusory area, thereby forming a colored semitransparent surface.

Several studies have shown that neon color spreading occurs when the luminance of the segments lies between the luminance of the background and that of the inducing elements (Anderson, 1997; Ekroll \& Faul, 2002; van Tuijl $\&$ de Weert, 1979). Bressan (1993) found that this condition can be violated, provided that the luminance relations between segments, inducing elements, and background support transparency. Indeed, many studies have concluded that there is a strong linkage between neon color spreading and transparency (e.g., Meyer \& Senecal, 1983; Nakayama, Shimojo, \& Ramachandran, 1990).

The segmentation of the luminances of a visual scene into a semitransparent overlay and a subjacent surface depends on the appropriate arrangement of $X$-junctions (e.g.,

M. Kavšek, kavsek@uni-bonn.de 


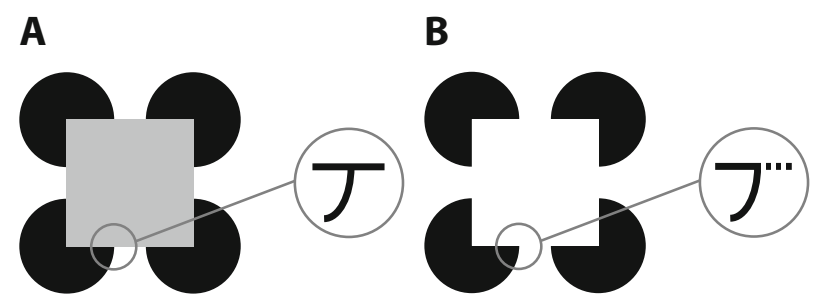

Figure 1. (A) If a real square overlaps disks, T-junctions are formed at the points of intersection. (B) In the subjective Kanizsa square, the L-junctions - that is, the tangent discontinuities at the tips of the Pacmen-function as implicit T-junctions. The implicit part of the enlarged $\mathrm{T}$-junction is symbolized by a broken line.

Cavanagh, 1987; Kersten, 1991). X-junctions are formed by the intersection of four regions with different luminances; such an intersection typically occurs in the region where a semitransparent surface overlaps opaque surfaces (see Figure 2A). The relations among these four intensities must adhere to certain rules (e.g., D'Zmura, Colantoni, Knoblauch, \& Laget, 1997; Masin, 1999; Metelli, 1985; Tommasi, 1999). Interestingly, in a neon color spreading display, (illusory) transparency is seen despite the fact that no X-junctions exist (see Figure 2B). Instead, the display contains T-junctions formed by the intersection of only three luminance values. T-junctions normally signal the interposition of two spatially separated opaque surfaces (see Figure 1A): The crossbar of the $\mathrm{T}$ is assumed to belong to the surface in front; the stem of the $\mathrm{T}$ is assumed to be part of the partially occluded surface. In Figure 2B, however, the crossbar of the $\mathrm{T}$ is assumed to belong to the partially occluded surface, and the stem of the $\mathrm{T}$ is assigned to the foreground surface. Furthermore, the luminance combination in the interposition situation of Figure $2 \mathrm{~B}$ is such that the luminance of the overlapping area is between that of the background and the Pacman elements. As a consequence, a subjective transparent contour-or rather, a neon color spreading area that is delimited by an illusory contouremerges. In this display, the T-junctions function as implicit X-junctions (e.g., Watanabe \& Cavanagh, 1993).

In both subjective contours (Figures $1 \mathrm{~B} / 3 \mathrm{~A}$ ) and neon color spreading figures (Figures 2B/4A), a sharp illusory border is perceived (illusory contour). According to Grossberg and Mingolla (1985; Grossberg, 1987a, 1987b, 1994; see also Grossberg \& Yazdanbakhsh, 2005), illusory contours are generated by the boundary contour system. This neurophysiological system is sensitive to the orientation and to the amount of contrast at luminance borders. It pools signals from opposite contrast polarities and synthesizes a boundary contour (see also Dresp \& Grossberg, 1997). In Peterhans, von der Heydt, and Baumgartner (1986; see also Dresp, 1997; Dresp \& Grossberg, 1997; Heitger \& von der Heydt, 1993), it is delineated that, in the subjective Kanizsa contour, the perpendicular edges where the curved contour of an inducing element terminates - that is, implicit T-junctions - activate specific end-stopped cells that are sensitive to boundaries that typically occur in occlusion situations. In a next step, these cells activate nearby detectors that then complete the gaps between the collinearly arranged corners of the Pacman elements (modal completion). Analogously, illusory contours in neon color spreading patterns are generated by implicit X-junctions. Grossberg and Mingolla further proposed that the illusory contour is filled in by the feature contour system. This system is sensitive to the direction and to the amount of contrast at luminance borders. It initiates a filling-in process that propagates featural qualities, such as brightness or color, up to the illusory contour generated by the boundary contour system. In the Kanizsa Figures 1B/3A, it effectuates an intensification of the brightness within the illusory contour (illusory bright$n e s s)$. In the neon color spreading Figures $2 \mathrm{~B} / 4 \mathrm{~A}$, it initiates a propagation of the quadrants' grayish color up to the boundaries of the illusory square. The result is a subjective semitransparent grayish square in front of a black background, partially occluding the four disks.

The boundary contour system and the feature contour system cause the illusory perception of the shape and of the surface characteristics of the illusory figure's foreground surface. In addition, adults normally amodally complete the inducing elements. In the cases of both the subjective Kanizsa square (Figures 1B/3A) and the neon color spreading figure (Figures $2 \mathrm{~B} / 4 \mathrm{~A}$ ), this means that adults perceive four circles, each of which is partially covered by the subjective square. The present study deals with young infant perception of the subjective surfaces in Figures $3 \mathrm{~A}$ and 4A, rather than with their ability to extract a depth stratification or to amodally complete the inducing elements.

Up until today, no experimental study on infant perception of neon color spreading figures has been published (but see Otsuka et al., in press). Infant perception of subjective contours, on the other hand, has been investigated in a number of experimental studies. These studies have provided contradictory evidence for the onset of sensitivity to subjective contours. On the one hand, Bertenthal, Campos, and Haith (1980) and Shapiro, Haith, Campos, Bertenthal, and Hazan (1983; cited by Haith, 1993) found that infants 7 months of age are able to extract a Kanizsa square. Infants 4 and 5 months of age failed to respond consistently to the subjective contour (see also Condry, Smith, \& Spelke, 2001; Csibra, Davis, Spratling, \& Johnson, 2000). On the other hand, Ghim (1990) reports that infants 3-4 months of age are apparently capable of perceiving a Kanizsa square. Furthermore, the results of an experiment conducted by Treiber and Wilcox (1980) suggest that infants 1-4 months of age react to a subjective Kanizsa triangle.

More recent research has taken up the contradiction between these studies by determining the emergence of the ability to perceive subjective contours. Several studies have demonstrated that younger infants are sensitive to subjective contours if the subjective pattern is embedded in a dynamic display (Curran, Braddick, Atkinson, Wattam-Bell, \& Andrew, 1999; Johnson \& Aslin, 1998; Kavšek \& Yonas, 2006; Otsuka \& Yamaguchi, 2003; Valenza \& Bulf, 2007). For example, according to Curran et al., infants 12-14 and 20-22 weeks of age are sensitive to an illusory line generated by aligned line terminators oscillating back and forth. In the experiments conducted by Kavšek and Yonas, infants 4 months of age responded to an illusory Kanizsa square 
A

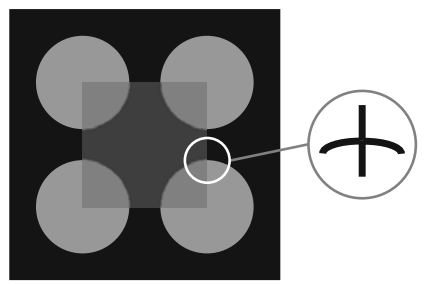

B

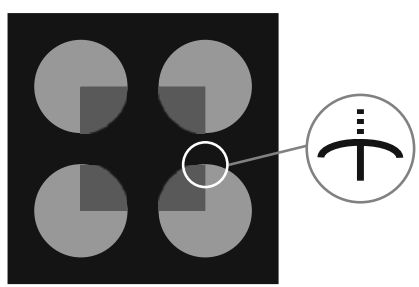

Figure 2. (A) If a semitransparent filter overlaps disks, X-junctions are formed at the points of intersection. (B) In a neon color spreading pattern, $\mathrm{T}$-junctions function as implicit $\mathrm{X}$-junctions (see enlarged area).

continuously moving back and forth in the horizontal plane. Motion may have facilitated the infant's performance in these studies because it attracted the infants' attention (e.g., Kaufmann, Stucki, \& Kaufmann-Hayoz, 1985). In line with the studies conducted by Ghim (1990) and Treiber and Wilcox (1980), more recent investigations have shown that infants 3-4 months of age are capable of extracting subjective contours even if there is no motion within the experimental display (Kavšek, 2002; Otsuka, Kanazawa, \& Yamaguchi, 2004; Sireteanu, 2000).

The goal of the first experiment was to contribute to the debate on whether or not infants as young as 4 months are responsive to subjective contours. Positive evidence for 4-month-old infants' ability to extract a subjective Kanizsa square would disprove the position that sensitivity to subjective contours emerges after about 5 months of age (e.g., Bertenthal et al., 1980).

According to Grossberg and Mingolla (1985), illusory contour and illusory brightness in subjective contours are triggered by the boundary contour system and by the feature contour system. Furthermore, these two neural mechanisms also generate illusory contour and color propagation in neon color spreading patterns. If, indeed, subjective contours and neon color spreading figures originate from the same neural mechanisms, it is reasonable to predict that 4-month-olds, given that they are capable of extracting the subjective Kanizsa square, respond to a neon color spreading pattern as well. This prediction was tested in the second experiment.

Before running the experiments, 50 undergraduates were shown three different versions of the subjective Kanizsa figure (Figure 3A) and the neon color spreading display (Figure 4A). The targets selected for the study were those eliciting the most discernible (subjective) effects. Overall, the participants rated the effects of each target to be very/quite convincing.

\section{EXPERIMENT 1}

In the main condition of the first experiment, infants 4 months of age were habituated to the subjective Kanizsa square depicted in Figure 3A and were afterward tested with Figure $3 \mathrm{~A}$ and the nonsubjective pattern in Figure 3B. Figure $3 \mathrm{~B}$ was constructed from Figure $3 \mathrm{~A}$ by rotating two inducing elements in such a way that the cutouts of the Pacmen did not form a square and, hence, did not evoke a subjective contour. If, indeed, infants 4 months of age are sensitive to the subjective square (Figure 3A), they should recognize it during the posthabituation phase and should discriminate it from the nonsubjective display shown in Figure 3B. More specifically, Figure 3B should be regarded as novel and should, therefore, attract the infants' attention. However, this looking pattern can also be a product of the participants' ability to detect the difference in figural symmetry and/or the local differences in the Pacman elements' orientation. To exclude this interpretation, a control condition was included (see also Bertenthal et al., 1980; Ghim, 1990). In this control condition, infants were habituated to the pattern in Figure 3C and were then confronted with the stimuli shown in Figures $3 \mathrm{C}$ and $3 \mathrm{~B}$. Figure $3 \mathrm{C}$ was derived from the Kanizsa pattern in Figure $3 \mathrm{~A}$ by rotating all inducing elements in such a way that their notches pointed outward. Like Figure 3A, Figure 3C is symmetric, but it does not contain a subjective contour. Furthermore, the overall amount of local differences between the displays shown in Figures $3 \mathrm{C}$ and $3 \mathrm{~B}$ equals the amount of local differences between the displays shown in Figures $3 \mathrm{~A}$ and $3 \mathrm{~B}$. In other words, in the main condition, the novel figure (3B) differed from the habituation figure $(3 \mathrm{~A})$ in that it was not symmetric, in that two inducing elements were rotated by $180^{\circ}$, and in that it induced no subjective contour. In the control condition, the difference between the experimental displays was only twofold. More specifically, the novel figure (3B) deviated from the habituation figure $(3 \mathrm{C})$ in that it was not symmetric and in that two inducing elements were rotated by $180^{\circ}$. Neither Figure 3C nor Figure 3B induced a subjective contour. Hence, the difference between the main and the control conditions consisted in the disappearance of a subjective square in the main condition, but not in the control condition. It was expected that the infants in the control condition would not differentiate between Figures $3 \mathrm{C}$ and $3 \mathrm{~B}$ - that is, that they would not react to the differences in symmetry or in the orientation of the Pacman elements. If so, it can be concluded that a positive finding in the main experimental condition is not generated by the infants' capability of discerning changes in symmetry or in the orientation of the Pacmen but originates from the infants' capability of discerning the presence or absence of the subjective contour. From the results of earlier investigations with younger infants, it was predicted that the participants would be able to respond to the subjective Kanizsa pattern (e.g., Kavšek, 2002; Otsuka et al., 2004). 
A

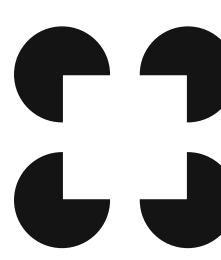

B

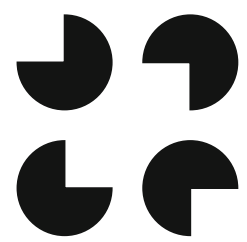

C

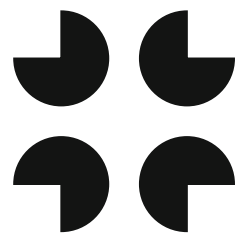

Figure 3. Experimental stimuli employed in Experiment 1. (A) Subjective Kanizsa square. Figures 3B and $3 \mathrm{C}$ are constructed from Figure $3 \mathrm{~A}$ by rotating two (B) and all (C) inducing elements, respectively.

\section{Method}

Participants. Forty 4-month-old, healthy, full-term infants composed the final sample (mean age $=124$ days, range $=$ 118-130 days). The participants were apportioned between the main and the control conditions. Thirty-seven additional babies were excluded from the analysis because of crying or fussiness $(n=14)$, failure to pass the criteria for moving into the posthabituation phase of the experiment $(n=8)$, experimenter error $(n=4)$, excessive parental involvement $(n=3)$, or extensive position bias during the trials in the posthabituation phase $(n=8)$, meaning that the infants looked at either the right or the left test pattern more than $80 \%$ of the available time (Haaf \& Diehl, 1976). Participant loss was higher in the main condition $(n=24)$ than in the control condition $(n=$ 13). In particular, all the participants who were excluded from the final sample due to experimenter error $(n=4)$ and parental involvement $(n=3)$ were tested in the main condition. The main condition was the first experimental condition in the experiment. Both experimenter errors and parental interference were minimized in the other experimental conditions. Furthermore, more infants who were excluded due to fussiness or crying and due to not habituating were tested in the main condition: $n=9$ and $n=7$ versus $n=5$ and $n=1$ in the control condition. A systematic reason for this difference could not be determined. The overall attrition rate due to fussiness, crying, and not habituating was high not only in Experiment 1, but also in Experiment 2. In both the experiments, the participants were recruited by letter and follow-up telephone calls. The names of the infants were obtained from birth records put at our disposal by the municipal authorities of the city of Bonn. Data protection was guaranteed. The infants' parents were provided with information about the visual abilities of infants, and small complimentary gifts were distributed among them.

Apparatus. Each infant sat in a reclining position on a parent's lap, $75 \mathrm{~cm}$ from a $155 \times 155 \mathrm{~cm}$ translucent, dull white, rearprojection screen. The stimuli were back-projected onto the screen, using a video projector. Two black side panels $(95 \times 182 \mathrm{~cm})$, which were oriented approximately $100^{\circ}$ from the front screen, blocked the experimental room and the observers from the infant's view. The room was dark except for light from the video projector and from two $25-\mathrm{W}$ bulbs, both positioned behind the infant.

Stimuli. The experimental stimuli included three drawings, which are outlined in Figures 3A, 3B, and 3C. The overall size of the experimental displays was adapted to the size of the subjective Ehrenstein contour display used by Kavšek (2002), which was clearly seen by 4-month-olds. This size was then used in the second experiment as well. When projected onto the screen, the overall dimensions of each slide were $80 \times 60 \mathrm{~cm}$ (visual angle, $46.8^{\circ} \times 38.7^{\circ}$ ). Each drawing consisted of four blue Pacman elements, each of which was created by deleting a quadrant from a circle measuring $3 \mathrm{~cm}$ (visual angle, $2.3^{\circ}$ ) in diameter. The distance from the center of one Pacman to the center of the next was $4 \mathrm{~cm}$ (visual angle, $3.05^{\circ}$ ). In Figure $3 \mathrm{~A}$, the Pacmen were arranged in such a way that the cutouts were directed inward, thereby inducing a subjective square. Figures $3 \mathrm{~B}$ and $3 \mathrm{C}-$ that is, the nonillusory targets - were constructed from Figure $3 \mathrm{~A}$ by rotating either two (Figure 3B) or all (Figure 3C) Pacmen by $180^{\circ}$. All the patterns were set against a yellow background.
Procedure. Each infant was brought to the laboratory by one parent and was then seated comfortably on that parent's lap. The parent was instructed not to interact with the baby during the experimental session. The goal of the study was not explained until the experiment was finished. The first slide showed a yellow display. A habituation-dishabituation design was employed. The habituation period followed an infant-controlled habituation procedure. Each habituation trial continued until the participant looked away from the stimulus display for $2 \mathrm{sec}$ or until $60 \mathrm{sec}$ of fixation time had elapsed after the infant had watched the display for at least $0.75 \mathrm{sec}$ continuously. Between trials, a yellow slide was presented for approximately 1-2 sec. The infant was judged to have habituated when, from the fourth fixation on, the sum of any three consecutive looking times was $50 \%$ or less than the sum of the looking times on the first 3 habituation trials. If the participant did not meet this criterion after 15 trials, the habituation phase was terminated, and the baby was excluded from the final sample. Once the criterion had been reached, the infant participated in 2 posthabituation trials. In each of these trials, the test stimuli were presented side by side until $10 \mathrm{sec}$ of looking time had elapsed. Hence, total looking time during the test trials amounted to $20 \mathrm{sec}$. The left-right position of the test patterns was counterbalanced across infants on the first test trial. Furthermore, positioning of the test displays was alternated from Trial 1 to Trial 2. Spatial separation of the test stimuli was $50 \mathrm{~cm}$ (visual angle, $33.7^{\circ}$ ), measured from center to center of the patterns.

Two experimenters observed the infant through $1 \times 1 \mathrm{~cm}$ peepholes in the side panels. The experimenters independently recorded how long the infant looked at the patterns by pressing buttons attached to a computer. The computer calculated the looking times and signaled the end of each trial, as well as signaling the end of the habituation and the dishabituation phases by a low-pitched tone. The experimenters could not see the stimuli on the rear-projection screen. Experimenter 2, however, watched the stimuli on a computer monitor and handled the sequence of the slides. Because Experimenter 1 was blind as to the stimulus on the screen at any given time, her data were used in the analyses. Experimenter 2 observed the participants to obtain a measure of interobserver agreement. In case of an experimenter error, the participant was excluded from the final sample only if the error had been made by Experimenter 1. As a result of this, Experimenter 2 contributed habituation data for 34 participants and dishabituation data for 37 participants. Interobserver agreement or Pearson correlation was $r=.90$ for total looking time from the habituation trials and $r=.91$ for looking times from the posthabituation trials.

\section{Results and Discussion}

Looking times toward the novel stimulus during the test trials and mean relative preferences for the novel stimulus are summarized in Table 1. First, the posthabituation data for the main experimental group were analyzed. The participants in this group were habituated to the subjective Kanizsa square (Figure 3A) and were subsequently tested for their ability to discriminate between Figures 3A and 3B. 
A

B

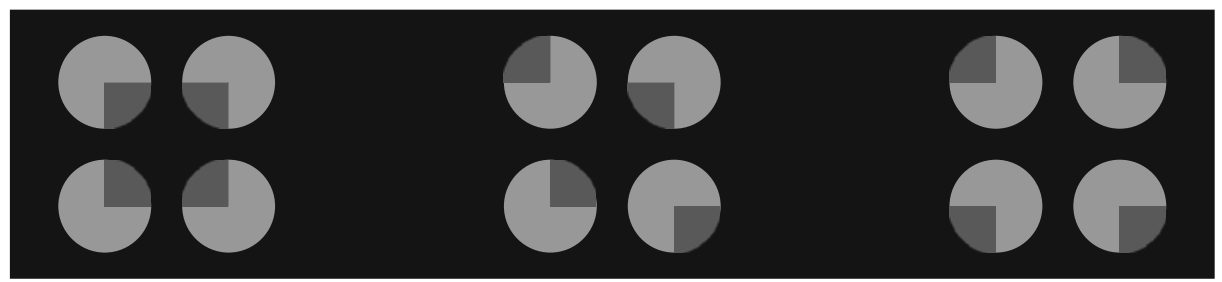

Figure 4. Experimental displays presented in Experiment 2. In panel A, adults perceive a subjective semitransparent square overlapping each of four disks. The figures shown in panels $\mathrm{B}$ and $\mathrm{C}$ are produced by rotating the inducing elements shown in Figure $4 \mathrm{~A}$.

To statistically scrutinize the effect of the habituation trials, a paired $t$ test was executed in order to compare the viewing times toward the test displays during the posthabituation trials. Statistical analysis revealed that, indeed, the participants looked significantly $(\alpha=.05)$ longer at Figure 3B (i.e., at the novel test pattern) than at Figure $3 \mathrm{~A}$ (i.e., at the familiar test display) $[t(19)=-2.81, p=.005$, one-tailed]. A one-tailed test was conducted because an overall longer looking at Figure 3B was predicted from earlier findings on young infants' perception of subjective contours.

Likewise, the test data for the control group were examined. Infants in this group were habituated to Figure 3C and were then confronted with Figures $3 \mathrm{C}$ and $3 \mathrm{~B}$. According to the $t$ statistics, looking times toward the test displays did not deviate significantly from each other $[t(19)=-0.08, p=.940$, two-tailed $]$.

In a third step, the novelty preference scores from both conditions were compared. More specifically, it was examined whether the relative preference for the novel test pattern was substantially larger in the main group than in the control group. Indeed, the $t$ statistics yielded a significant difference between the groups $[t(38)=-1.84$, $p=.036$, one-tailed], in that the infants in the main group looked significantly longer at the novel target (Figure 3B) than did the infants in the control group.

As was expected, the participants in the main experimental group were capable of discriminating between the subjective Kanizsa display depicted in Figure 3A and the nonillusory pattern shown in Figure 3B. One might object, however, that this performance originated from the infants' ability to perceive the difference in symmetry or the local differences in the orientation of the Pacmen. The findings for the control group, however, ran counter to this argument. After being habituated to Figure 3C, the participants in this group evidently did not regard the test target shown in Figure 3B as novel even though the local differences and the difference in symmetry between Patterns 3B and 3C were made equal to the local differences and the difference in symmetry between the test displays in the main condition - that is, between the targets shown in Figures $3 \mathrm{~B}$ and $3 \mathrm{~A}$. Moreover, a statistical comparison of the data for both conditions showed that the difference in degree of dishabituation between the conditions is statistically reliable. From that, one can deduce that the 4-month-olds' looking behavior in the main condition was apparently based on the disappearance of the subjective square in the novel test target (Figure 3B).

\section{EXPERIMENT 2}

The purpose of the second experiment was to extend the findings of Experiment 1 to a neon color spreading figure. In a manner analogous to Experiment 1, infants 4 months of age were habituated to the neon color spreading display shown in Figure 4A and were subsequently tested for their ability to discriminate this display from a nonillusory target with rotated inducing elements (Figure 4B). Likewise, infants in a control group were examined on their capability of perceiving the difference in symmetry and the local differences between the nonillusory patterns shown in Figures 4C and 4B.

Table 1

Average Looking Times (in Seconds, With Standard Deviations) Toward the Novel Test Pattern of Each Experimental Condition

\begin{tabular}{|c|c|c|c|c|c|c|c|}
\hline \multirow[b]{2}{*}{ Experiment and Habituation Display } & \multicolumn{2}{|c|}{$\begin{array}{c}\text { Mean } \\
\text { Habituation } \\
\text { Duration }\end{array}$} & \multirow{2}{*}{$\begin{array}{c}\text { Novel } \\
\text { Test } \\
\text { Pattern }\end{array}$} & \multicolumn{2}{|c|}{$\begin{array}{c}\text { Mean Looking } \\
\text { Time Toward the } \\
\text { Novel Test Pattern } \\
\end{array}$} & \multicolumn{2}{|c|}{$\begin{array}{c}\text { Mean Relative } \\
\text { Preference for the } \\
\text { Novel Test Pattern }\end{array}$} \\
\hline & $M$ & $S D$ & & $M$ & $S D$ & $M$ & $S D$ \\
\hline \multicolumn{8}{|l|}{ Experiment 1} \\
\hline Figure 3A (subjective contour) & 134.93 & 78.36 & Figure $3 \mathrm{~B}$ & $11.54^{*}$ & 2.41 & 57.57 & 0.12 \\
\hline Figure $3 \mathrm{C}$ & 126.86 & 74.27 & Figure $3 \mathrm{~B}$ & 10.06 & 2.64 & 50.22 & 0.13 \\
\hline \multicolumn{8}{|l|}{ Experiment 2} \\
\hline Figure 4A (neon color spreading display) & 120.82 & 79.72 & Figure 4B & $11.16^{* *}$ & 2.16 & 55.69 & 0.11 \\
\hline Figure $4 \mathrm{C}$ & 91.14 & 42.72 & Figure 4B & 9.84 & 1.71 & 49.17 & 0.08 \\
\hline
\end{tabular}




\section{Method}

Participants. The experiment was conducted on a sample of 40 infants who were 4 months of age (mean age $=125$ days, range $=$ 118-130 days). Twenty infants participated in the main condition; the remaining 20 infants were assigned to the control condition. Thirty additional participants were tested but not included in the final sample, due to their becoming fussy and crying $(n=14)$, their failure to pass the criteria to move into the dishabituation phase $(n=8)$, experimenter error $(n=2)$, parental interference $(n=1)$, or position bias during the dishabituation period $(n=5)$. Seventeen infants were excluded from the main condition; 13 infants were excluded from the control condition.

Participant loss in both experiments was relatively high. This might be due partly to a very strict implementation of the inclusion criteria for the final sample. Especially the threshold for terminating the experimental session when a baby started to become fidgety was quite low. In addition, the experimental pictures were static: Presumably, many infants did not complete the experimental session because the attention-attracting value of the displays was relatively low.

Apparatus and Procedure. The apparatus and experimental procedure were identical to those in Experiment 1. Interjudge reliability was high: $r=.95(n=32)$ for the habituation data and $r=$ $.87(n=38)$ for the looking times from the test trials.

Stimuli. The three stimuli used are shown in Figure 4. Each pattern consisted of four yellow circles in which the color of one quadrant of each was toned down to such an extent that it appeared grayish-yellow. The background within each display was black. The overall dimensions of each target were exactly the same as those in Figure 3. In the neon color spreading display (see Figure 4A), adults report perceiving a grayish filter in front of opaque yellow circles.

\section{Results and Discussion}

According to Table 1, the participants in the main experimental condition looked longer at the nonillusory test display (Figure 4B) than at the illusory test display (Figure $4 \mathrm{~A}$ ). Indeed, the difference between viewing times turned out to be significant $[t(19)=2.36, p=.014$, onetailed]. Infants in the control condition, on the other hand, obviously did not detect the difference between the nonsubjective targets in Figures 4C and 4B $[t(19)=-0.43$, $p=.669$, two-tailed]. The novelty preference in the main group was reliably stronger than that in the control group $[t(38)=-2.15, p=.019$, one-tailed $]$.

These results confirm that, indeed, infants 4 months of age are apparently able to respond to the illusory effect induced by the neon color spreading pattern portrayed in Figure 4A. The participants in the main condition could discriminate this pattern from a nonsubjective target (Figure 4B), but the infants in the control condition were not capable of reacting to the difference between the nonillusory displays shown in Figures 4C and 4B. The apparent failure of the infants in the control condition to distinguish between the nonillusory targets (4B and 4C) indicates that the infants in the main condition reacted to the illusory effect in Figure 4A, instead of solely scenting out the difference in symmetry or the local rotation differences between the displays shown in Figures 4B and 4A.

\section{GENERAL DISCUSSION}

The first experiment was designed to test the hypothesis that infants 4 months of age are able to perceive subjective contours. In some studies, it has been observed that this ability does not exist until about 5-7 months of age (e.g., Bertenthal et al., 1980). Other investigations, however, have shown that even infants 3-4 months of age are able to extract subjective contours (e.g., Ghim, 1990). The main condition of the experiment demonstrated that participants 4 months of age could discriminate between a subjective Kanizsa square (Figure 3A) and a nonsubjective figure (Figure 3B). Infants in a control condition, however, failed to differentiate between two nonsubjective displays (Figures 3C and 3B), although the local differences and the difference in symmetry between these displays equaled the local differences and the difference in symmetry between the test displays in the main condition. These differences arise from the fact that the inducers - that is, the Pacman elements - possess various orientations. The result of the control condition indicates that the significant dishabituation behavior in the main condition originated primarily in the presence of the subjective contour in Figure $3 \mathrm{~A}$ and the absence of this contour in Figure 3B. Hence, the findings of Experiment 1 confirm the results reported in more recent research by demonstrating that infants 4 months of age are able to respond to a subjective contour (e.g., Kavšek, 2002; Otsuka et al., 2004; Sireteanu, 2000).

The second experiment, the design of which followed exactly the procedure in Experiment 1, explored young infants' perception of neon color spreading figures (see Figure 4A). Indeed, evidence was obtained that this ability is present in 4-month-old infants (see also Otsuka et al., in press).

One might object that the preference for the nonillusory test figure in the main condition of each experiment did not result from the preceding habituation to the illusory figure but reflected a preexisting natural preference for the nonillusory patterns shown in Figures 3B and 4B over the illusory ones shown in Figures 3A and 4A. This natural preference might be due to the complexity of the outer stimulus contours: Stimuli $3 \mathrm{~B} / 4 \mathrm{~B}$ and $3 \mathrm{C} / 4 \mathrm{C}$ contain abrupt and angular notches (3B and $3 \mathrm{C}$ ) or color irregularities (4B and 4C) in their outer contour, whereas the illusory patterns shown in Figures 3A and 4A have smooth, rounded, and uniform outer contours. According to the objection, because of the higher complexity of their outer contours, the nonillusory patterns $(3 \mathrm{~B} / 3 \mathrm{C}$ and $4 \mathrm{~B} / 4 \mathrm{C})$ are naturally preferred over the illusory ones shown in Figures $3 \mathrm{~A}$ and $4 \mathrm{~A}$. In the light of the studies conducted by Otsuka et al. (2004) and by Kavšek and Yonas (2006), however, this natural preference is unlikely. Both studies showed a spontaneous preference for the subjective Kanizsa square over nonillusory contours - that is, a natural preference in the opposite direction. More specifically, with participants 3-4 months of age, Otsuka et al. (2004) observed clear natural preferences for the subjective Kanizsa contour over two nonillusory patterns, which were comparable to the nonillusory patterns shown in Figures 3B and 3C. Furthermore, if indeed the nonillusory stimuli attract infants' attention more than do the illusory figures, both Pattern $3 \mathrm{C}$ and Pattern 4C should evoke longer looking times during the habituation period (control conditions) than do the illusory patterns shown in Figures 3A and 4A (main conditions). According to Table 1, mean total looking/habituation duration was $126.86 \mathrm{sec}(S D=74.27 \mathrm{sec})$ for Pattern $3 \mathrm{C}$ and 
$91.14 \sec (S D=42.72)$ for Pattern 4C. These looking times are smaller than the mean looking/habituation durations for the illusory figures, which amount to $134.93 \mathrm{sec}(S D=$ $78.36 \mathrm{sec})$ for Pattern $3 \mathrm{~A}$ and to $120.82 \mathrm{sec}(S D=79.72$ $\mathrm{sec}$ ) for Pattern 4A. Again, this observation runs counter to the hypothesis that the nonillusory stimuli are more attractive than the illusory figures.

A further argument against the significance of the study maintains that instead of responding to the presence or absence of the illusory phenomenon, the infants in the main condition of each experiment simply reacted to specific changes within the outer contours. More specifically, the infants in the main conditions displayed a dishabituation reaction, because the habituation patterns shown in Figures 3A and 4A had only smooth, rounded, and uniform outer contours and, hence, were perceptually very different from the test patterns shown in Figures 3B and $4 \mathrm{~B}$, which contained either angular cutoffs (3B) or color irregularities (4B) in their outer contours. In the control conditions, both the habituation stimulus and the novel stimulus had sharp discontinuities/irregularities in their outer contours, meaning that their difference was less salient. Accordingly, the participants showed no significant dishabituation. This interpretation maintains that 4-month-old infants are biased toward external pattern information and that the perceptual stimulus difference in the main conditions was stronger than that in the control conditions. Indeed, several studies have shown that very young infants tend to focus their attention on the peripheral features of visual patterns (e.g., Bushnell, 1979; Maurer, 1983). However, research on this externality effect also has shown that from about 2 months of age on, infants tend to fixate internal stimulus elements equally or even preferentially (e.g., Klitsch \& Woodruff, 1985; Milewski, 1976; Salapatek, 1975). Furthermore, the argument that the participants detected interruptions in continuous outer contours (i.e., a change from Stimulus $3 \mathrm{~A} / 4 \mathrm{~A}$ to Stimulus $3 \mathrm{~B} / 4 \mathrm{~B}$ ) but not interruptions in discontinuous outer contours (i.e., a change from Stimulus $3 \mathrm{C} / 4 \mathrm{C}$ to Stimulus 3B/4B) implicates a perceptual bias toward discontinuities in visual patterns: Outer contour discontinuities attract the infants' attention if they are not present in the familiar pattern but crop up in the novel pattern, thereby eliciting a novelty reaction in the main conditions, whereas no dishabituation response can be induced by adding some continuities to a discontinuous pattern (control conditions). In other words, the infants in the control conditions just noticed that discontinuous outer contour sections were present in both experimental arrays. Accordingly, they regarded these arrays as equivalent. In the main conditions, on the other hand, discontinuities were present in the novel stimulus only. As a consequence, these discontinuities attracted the infants' attention, thereby generating a significant dishabituation response. To summarize, it is, hence, again postulated that the infants' looking was controlled by a natural preference for visual displays with cutoffs or color irregularities in their outer contours over displays with rounded and uniform outer contours. It has already been delineated that this hypothesis has been disproved by empirical studies according to which the illusory Kanizsa square is naturally preferred over nonillusory patterns (e.g., Otsuka et al., 2004). In line with this, furthermore, looking/ habituation times toward the illusory Figures $3 \mathrm{~A}$ and $4 \mathrm{~A}$ were longer, rather than shorter, than looking/habituation times for the nonillusory Figures $3 \mathrm{C}$ and $4 \mathrm{C}$. Finally, in a previous study, the author of the present article has shown that 4-month-old infants are able to extract a subjective Ehrenstein illusion created by radial lines (Kavšek, 2002). Most interesting, in that study, the habituation stimulus in the control condition had a continuous outer contour, whereas both the illusory figure and the nonillusory figure, which served as the novel display in both experimental conditions, had discontinuous outer contours. The infants detected the difference between the stimuli in the main condition - that is, between two stimuli, both of which had discontinuous outer contours. On the other hand, they did not respond to the difference between the stimuli in the control condition - that is, between a figure with external continuities and a figure with external discontinuities. This result contradicts the argument that 4-month-old infants display a significant dishabituation response if the novel test display's outer contour is discontinuous, whereas, on the contrary, the habituation figure's outer contour is continuous. Nevertheless, future research is needed to more deeply elucidate the relationship between the illusory and the nonillusory patterns that were investigated in the present experiments.

The subjective Kanizsa square shown in Figure 3A contains two illusory effects: illusory contour and illusory brightness. Similarly, the neon color spreading display shown in Figure 4A comprises an illusory contour and the spreading of color across the area enclosed by the illusory contour. According to Grossberg and Mingolla (1985), perception of illusory contour is mediated through the boundary contour system. Illusory brightness in subjective contours and color propagation in neon color spreading displays, on the other hand, are triggered by the feature contour system. For subjective contours, Experiment 1 substantiates that these systems are operating by 4 months of age. The model proposed by Grossberg and Mingolla is not restricted to an explanation of subjective contours but claims to be applicable to neon color spreading patterns as well. If this basic assumption holds true-that is, if both perceptual phenomena, subjective contours and neon color spreading, can be accounted for by the same neurophysiological components-4-month-old infants should be able to react not only to subjective contours (Experiment 1), but also to neon color spreading patterns. Indeed, Experiment 2 validates the Grossberg and Mingolla model by demonstrating that 4-month-old infants obviously process subjective transparent contours - that is, neon color spreading contours.

Unfortunately, as has also been the case in most prior research on subjective contours, neither Experiment 1 nor Experiment 2 unequivocally establishes which effect was extracted by the participants - that is, which of the underlying neurophysiological processes was operating in the infants. In subjective contours, illusory brightness can be eliminated by using inducing elements carrying oppo- 
site contrast polarities. In fact, both Curran et al. (1999) and Kavšek and Yonas (2006) found that young infants are sensitive to subjective contours with alternating black and white inducing elements in front of a middle-gray background. In these figures, illusory contour, but not illusory brightness, can be seen because the local signals of differential brightness generated by the individual inducing elements cancel each other out (e.g., Dresp, SalvanoPardieu, \& Bonnet, 1996; Prazdny, 1983). Hence, the results of both studies provide evidence for young infants' ability to fill the gaps between the inducing elements and to discern the illusory contour. It can, therefore, be conjectured that the participants in Experiment 1, when seeing the subjective Kanizsa square shown in Figure 3A, probably extracted the illusory contour. However, whether the neurophysiological filling-in mechanisms involved in illusory contour formation can be activated in young infants not only by subjective contours, but also by neon color spreading patterns, is an open question. The results of Experiment 2 leave open the question of to which illusory phenomenon-illusory contour, color spreading, or both - the infants were responding. Unfortunately, ifanalogous to the studies conducted by Curran et al. and by Kavšek and Yonas - the neon color spreading display shown in Figure 4A is transformed into a stimulus with inducing disks of varying signs, an illusory semitransparent square can still be seen. Future research has to solve the task of disentangling illusory contour perception and extraction of neon color/luminance spreading by constructing adequate experimental stimuli. For example, one might violate the color/luminance relations within a neon color spreading display in such a way that they are incompatible with transparency. As a result, neon color/ luminance propagation is canceled (e.g., Anderson, 1997; Bressan, Mingolla, Spillmann, \& Watanabe, 1997). If the infants still react to the neon color spreading figure, it can be concluded that illusory contour formation contributes significantly to the infants' experimental performance. Interestingly, both Johnson and Aslin (2000) and Otsuka, Kanazawa, and Yamaguchi (2006) have explored infant sensitivity to X-junctions. According to the results of Johnson and Aslin (2000), 4-month-old infants are able to extract transparency from a chromatic visual display. Otsuka et al. (2006) found similar results in 3- to 4-montholds' perception of achromatic patterns (but see Kavšek, in press). In light of these observations, one can suppose that extraction of neon color propagation - that is, of illusory transparency - which is strongly related to the perception of transparency (e.g., Bressan, 1993), is present in 4-month-old infants as well.

In short, the role of both the boundary contour system (illusory contour formation) and the feature contour system (illusory color propagation) in 4-month-olds' perception of neon color spreading figures needs further exploration. The present experiments do not supply clear evidence for the contribution of either factor. More specifically, one must remove each of the illusory phenomena separately from the neon color spreading pattern in order to bring out their influence (e.g., Watanabe \& Sato, 1989). Nevertheless, the present experiments extend prior research by pro- viding evidence for 4-month-olds' sensitivity not only to implicit T-line junctions (subjective contours), but also to implicit X-line junctions (neon color spreading patterns).

Another aspect that should be investigated by future research is the infant's ability to extract the amodal aspects of neon color spreading figures. For the subjective Kanizsa square, Condry et al. (2001) could show that infants 7, but not 4 , months of age are apparently able to perceive the inducing circles as continuing behind the illusory square. In addition, Csibra (2001) found that 8-month-olds, but not 5-month-olds, perceive the illusory Kanizsa square as an occluding surface. Whether similar age trends can be found for the amodal characteristics of neon color spreading patterns is an open question.

\section{AUTHOR NOTE}

This study was supported by the Deutsche Forschungsgemeinschaft (DFG). It was conducted as a part of the research project "Perceptual Development in Infancy" (KA 1123/6-2). The project was affiliated with the DFG research group "Cognitive Development." I thank Laura Hemker, Sabrina Blawath, Catharina Degenhardt, Hyeri Kim, Margarete Kloss, and Julia Niehl for research assistance. Thanks are especially extended to the infants and parents who participated in the study. I am also grateful to the reviewers for their valuable comments and suggestions. Correspondence concerning this article should be addressed to M. Kavšek, Department of Psychology, University of Bonn, Kaiser-Karl-Ring 9, 53111 Bonn, Germany (e-mail: kavsek@uni-bonn.de).

\section{REFERENCES}

Albert, M. K. (1999). Surface formation and depth in monocular scene perception. Perception, 28, 1347-1360. doi:10.1068/p2987

Anderson, B. L. (1997). A theory of illusory lightness and transparency in monocular and binocular images: The role of contour junctions. Perception, 26, 419-453. doi:10.1068/p260419

Bertenthal, B. I., Campos, J. J., \& Haith, M. M. (1980). Development of visual organization: The perception of subjective contours. Child Development, 51, 1072-1080.

BRESSAN, P. (1993). Revisitation of the luminance conditions for the occurrence of the achromatic neon color spreading illusion. Perception \& Psychophysics, 54, 55-64.

Bressan, P., Mingolla, E., Spillmann, L., \& Watanabe, T. (1997). Neon color spreading: A review. Perception, 26, 1353-1366. doi:10.1068/p261353

Bushnell, I. (1979). Modification of the externality effect in young infants. Journal of Experimental Child Psychology, 28, 211-229. doi:10.1016/0022-0965(79)90085-7

Cavanagh, P. (1987). Reconstructing the third dimension: Interactions between color, texture, binocular disparity, and shape. Computer Vision, Graphics, \& Image Processing, 37, 171-195.

Condry, K. F., Smith, W. C., \& Spelke, E. S. (2001). Development of perceptual organization. In F. Lacerda, C. von Hofsten, \& M. Heimann (Eds.), Emerging cognitive abilities in early infancy (pp. 1-28). Mahwah, NJ: Erlbaum.

Csibra, G. (2001). Illusory contour figures are perceived as occluding surfaces by 8 -month-old infants. Developmental Science, 4, F7-F11. doi:10.1111/1467-7687.00179

Csibra, G., Davis, G., Spratling, M. W., \& Johnson, M. H. (2000). Gamma oscillations and object processing in the infant brain. Science, 290, 1582-1585. doi:10.1126/science.290.5496.1582

Curran, W., Braddick, O. J., AtKinson, J., Wattam-Bell, J., \& ANDREW, R. (1999). Development of illusory-contour perception in infants. Perception, 28, 527-538. doi:10.1068/p2845

Dresp, B. (1997). On "illusory" contours and their functional significance. Cahiers de Psychologie Cognitive, 16, 489-518.

Dresp, B., \& Grossberg, S. (1997). Contour integration across polarities and spatial gaps: From local contrast filtering to global grouping. Vision Research, 37, 913-924. doi:10.1016/S0042-6989(96)00227-1

Dresp, B., Salvano-Pardieu, V., \& Bonnet, C. (1996). Illusory form 
with inducers of opposite contrast polarity: Evidence for multistage integration. Perception \& Psychophysics, 58, 111-124.

D'Zmura, M., Colantoni, P., Knoblauch, K., \& Laget, B. (1997). Color transparency. Perception, 26, 471-492. doi:10.1068/p260471

Ekroll, V., \& FAUL, F. (2002). Perceptual transparency in neon color spreading displays. Perception \& Psychophysics, 64, 945-955. doi: $10.1068 / \mathrm{p} 3240$

GHIM, H. (1990). Evidence for perceptual organization in infants: Perception of subjective contours by young infants. Infant Behavior \& Development, 13, 221-248. doi:10.1016/0163-6383(90)90032-4

Grossberg, S. (1987a). Cortical dynamics of three-dimensional form, color, and brightness perception: I. Monocular theory. Perception \& Psychophysics, 41, 87-116.

GrossberG, S. (1987b). Cortical dynamics of three-dimensional form, color, and brightness perception: II. Binocular theory. Perception \& Psychophysics, 41, 117-158.

Grossberg, S. (1994). 3-D vision and figure-ground separation by visual cortex. Perception \& Psychophysics, 55, 48-120.

Grossberg, S., \& Mingolla, E. (1985). Neural dynamics of form perception: Boundary completion, illusory figures, and neon color spreading. Psychological Review, 92, 173-211. doi:10.1037/0033 $-295 X .92 .2 .173$

Grossberg, S., \& YazdanbaKhsh, A. (2005). Laminar cortical dynamics of 3D surface perception: Stratification, transparency, and neon color spreading. Vision Research, 45, 1725-1743. doi:10.1016/j visres.2005.01.006

HaAf, R. A., \& Diehl, R. E. (1976). Position bias and the pairedcomparison procedure in studies of infant attention. Developmental Psychology, 12, 548-549. doi:10.1037/0012-1649.12.6.548

Haith, M. M. (1993). Preparing for the 21st century: Some goals and challenges for studies of infant sensory and perceptual development. Developmental Review, 13, 354-371. doi:10.1006/drev.1993.1017

HeITGER, F., \& VON DER HEYDT, R. (1993). A computational model of neural contour processing: Figure-ground segregation and illusory contours. In Proceedings of the 4th International Conference on Computer Vision (pp. 32-40). Los Alamitos, CA: IEEE Computer Society Press.

Johnson, S. P., \& Aslin, R. N. (1998). Young infants' perception of illusory contours in dynamic displays. Perception, 27, 341-353. doi: $10.1068 / \mathrm{p} 270341$

Johnson, S. P., \& Aslin, R. N. (2000). Infants' perception of transparency. Developmental Psychology, 36, 808-816. doi:10.1037/0012 $-1649.36 .6 .808$

Kanizsa, G. (1976). Subjective contours. Scientific American, 234, 48-52.

Kaufmann, F., Stucki, M., \& Kaufmann-Hayoz, R. (1985). Development of infants' sensitivity for slow and rapid motions. Infant Behavior \& Development, 8, 89-98. doi:10.1016/S0163-6383(85)80019-9

KAVŠEK, M. J. (2002). The perception of static subjective contours in infancy. Child Development, 73, 331-344. doi:10.1111/1467 $-8624.00410$

KAVŠEK, M. [J.] (in press). Infant perception of static two-dimensional transparency information. European Journal of Developmental Psychology. doi:10.1080/17405620601095300

KavŠEK, M. [J.], \& Yonas, A. (2006). The perception of moving subjective contours by 4-month-old infants. Perception, 35, 215-227. doi:10.1068/p5260

KerSTEN, D. (1991). Transparency and the cooperative computation of scene attributes. In M. S. Landy \& J. A. Movshon (Eds.), Computational models of visual processing (pp. 209-228). Cambridge, MA: MIT Press.

KLiTSCH, E. S., \& WoodrufF, D. S. (1985). Compound pattern perception in early infancy. Child Study Journal, 15, 1-12.

Masin, S. C. (1999). Color scission and phenomenal transparency. Perceptual \& Motor Skills, 89, 815-823. doi:10.2466/PMS.89.7.815

MAURER, D. (1983). The scanning of compound figures by young infants. Journal of Experimental Child Psychology, 35, 437-448. doi:10.1016/0022-0965(83)90019-X

Metelli, F. (1985). Stimulation and perception of transparency. Psychological Research, 7, 185-202. doi:10.1007/BF00309446
Meyer, G. E., \& Senecal, M. (1983). The illusion of transparency and chromatic subjective contours. Perception \& Psychophysics, $\mathbf{3 4}$ $58-64$.

MiLEwSKI, A. E. (1976). Infants' discrimination of internal and external pattern elements. Journal of Experimental Child Psychology, 22, 229246. doi:10.1016/0022-0965(76)90004-7

Nakayama, K., Shimojo, S., \& Ramachandran, V. S. (1990). Transparency: Relation to depth, subjective contours, luminance, and neon color spreading. Perception, 10, 497-513. doi:10.1068/p190497

Otsuka, Y., KanaZawa, S., \& Yamaguchi, M. K. (2004). The effect of support ratio on infants' perception of illusory contours. Perception, 33, 807-816. doi: $10.1068 / \mathrm{p} 5129$

Otsuka, Y., Kanazawa, S., \& Yamaguchi, M. K. (2006). Perceptual transparency in 3- to 4-month-old infants. Perception, 35, 1625-1636. doi:10.1068/p5386

OTsuKa, Y., \& YAMAGUChI, M. K. (2003). Infants' perception of illusory contours in static and moving figures. Journal of Experimental Child Psychology, 86, 244-251. doi:10.1016/S0022-0965(03)00126-7

Otsuka, Y., Yamazaki, Y., Konishi, Y., KanaZawa, S., Yamaguchi, M. K., \& SPEHAR, B. (in press). The perception of illusory transparent surfaces in infancy: Early emergence of sensitivity to static pictorial cues. Journal of Vision.

Peterhans, E., von der Heydt, R., \& Baumgartner, G. (1986). Neuronal responses to illusory contour stimuli reveal stages of visual cortical processing. In J. D. Pettigrew, K. J. Sanderson, \& W. R. Levick (Eds.), Visual neuroscience (pp. 343-351). Cambridge: Cambridge University Press.

PRAZDNY, K. (1983). Illusory contours are not caused by simultaneous brightness contrast. Perception \& Psychophysics, 34, 403-404.

Salapatek, P. (1975). Pattern perception in early infancy. In L. B. Cohen \& P. Salapatek (Eds.), Infant perception: From sensation to cognition. Vol. I: Basic visual processes (pp. 133-248). New York: Academic Press.

Shapiro, B., Haith, M. M., Campos, J., Bertenthal, B., \& Hazan, C. (1983, November). Motion enhances object perception for infants. Paper presented at the Annual Meeting of the Psychonomic Society, San Diego.

Sireteanu, R. (2000). Texture segmentation, "pop-out," and feature binding in infants and children. In C. Rovee-Collier, L. P. Lipsitt, \& H. Hayne (Eds.), Progress in infancy research (Vol. 1, pp. 183-249). Mahwah, NJ: Erlbaum.

Tommasi, M. (1999). A ratio model of perceptual transparency. Perceptual \& Motor Skills, 89, 891-897. doi:10.2466/PMS.89.7.891

Treiber, F., \& Wilcox, S. (1980). Perception of a "subjective" contour by infants. Child Development, 51, 915-917. doi:10.2307/1129486

VAlenza, E., \& Bulf, H. (2007). The role of kinetic information in newborns' perception of illusory contours. Developmental Science, 10, 492-501. doi:10.1111/j.1467-7687.2007.00602.x

van TuisL, H. F. J. M. (1975). A new visual illusion: Neonlike color spreading and complementary color induction between subjective contours. Acta Psychologica, 39, 441-445. doi:10.1016/0001 $-6918(75) 90042-6$

van TuiJl, H. F. J. M., \& De Weert, C. M. (1979). Sensory conditions for the occurrence of the neon spreading illusion. Perception, $\mathbf{8}, 211$ 215. doi:10.1068/p080211

VARIN, D. (1971). Fenomeni di contrasto e diffusione cromatica nell'organizzazione spaziale del campo percettivo. Rivista di Psicologia, 65, 101-128.

Watanabe, T., \& Cavanagh, P. (1993). Transparent surfaces defined by implicit X junctions. Vision Research, 33, 2339-2346. doi:10.1016/0042-6989(93)90111-9

Watanabe, T., \& Sato, T. (1989). Effects of luminance contrast on color spreading and illusory contour in the neon color spreading effect. Perception \& Psychophysics, 45, 427-430.

(Manuscript received January 17, 2008; revision accepted for publication September 16, 2008.) 